\title{
Psychosocial Factors and Coronary Calcium in Adults without Clinical Cardiovascular Disease
}

Ana V. Diez Roux, MD, PhD; Nalini Ranjit, PhD; Lynda Powell, PhD; Sharon Jackson, PhD; Tené T. Lewis, PhD; Steven Shea, MD; and Colin Wu, PhD

Background: Psychosocial factors have been linked to coronary events, but the mechanisms underlying these associations have not been established. Evidence is mixed regarding associations of psychosocial factors with subclinical coronary atherosclerosis.

Objective: To examine associations of 4 psychosocial factors (depressive symptoms, anger, anxiety, and chronic stress) with the presence of subclinical coronary atherosclerosis.

Design: Cross-sectional study.

Setting: The Multiethnic Study of Atherosclerosis, a populationbased study of subclinical atherosclerosis.

Patients: A multiethnic sample of 6789 adults, 45 to 84 years of age, with no history of clinical cardiovascular disease.

Measurements: Coronary calcium was assessed by using chest computed tomography, and psychosocial factors were assessed by using questionnaires with validated scales.

Results: There was no evidence that higher levels of the psychosocial measures were associated with greater prevalence of calcifi- cation or with greater amounts of calcium among persons with calcium. Age- and risk factor-adjusted relative prevalences of coronary calcification in men for the top fourth category versus the bottom fourth category of anger, anxiety, and depressive symptoms were $0.94(95 \% \mathrm{Cl}, 0.88$ to 1.01$), 0.97(\mathrm{Cl}, 0.90$ to 1.04$)$, and $0.97(\mathrm{Cl}, 0.90$ to 1.05$)$, respectively; these values for women were $1.01(\mathrm{Cl}, 0.90$ to 1.15$), 0.93(\mathrm{Cl}, 0.83$ to 1.05$)$, and $0.92(\mathrm{Cl}$, 0.82 to 1.04$)$, respectively. Relative prevalences for the top versus the bottom category of chronic stress burden were $1.02(\mathrm{Cl}, 0.94$ to 1.11) for men and $0.88(\mathrm{Cl}, 0.79$ to 0.99$)$ for women.

Limitations: Current measures of psychosocial factors may be a poor proxy for cumulative exposure during development of atherosclerosis.

Conclusion: Depressive symptoms, anger, anxiety, and chronic stress burden were not associated with coronary calcification in a multiethnic sample of asymptomatic adults.

Ann Intern Med. 2006;144:822-831.

www.annals.org

For author affiliations, see end of text.
$\mathrm{T}$ he extent to which psychosocial factors are important risk factors for coronary heart disease has been debated (1-3). Measures of depression, anxiety, hostility, and anger have been shown to be associated with coronary heart disease in prospective studies (4-8). When present, these associations seem to be independent of behavioral risk factors. The biological mechanisms through which psychosocial factors exert their effects have not been fully elucidated. The recent emergence of markers of subclinical atherosclerosis allows investigation of whether psychosocial factors are related to early asymptomatic disease.

Psychosocial factors may be related to atherosclerosis through their association with behavioral risk factors, such as smoking, physical activity, and diet. Psychosocial factors may also directly affect biological processes, such as inflammation $(9-11)$, hemostasis $(12,13)$, cardiovascular reactivity $(14,15)$, endothelial injury and endothelial function (16-18), platelet activation (19-21), autonomic function $(22,23)$, and abdominal obesity $(24)$, that are involved in the development of atherosclerosis. These biological effects may be mediated in part through effects of psychosocial factors on the hypothalamic-pituitary-adrenal axis and the sympathetic and parasympathetic nervous systems (25).

The presence and amount of coronary calcium have recently emerged as markers of subclinical coronary atherosclerosis (26-28). Only 4 studies have investigated associations of psychosocial factors with coronary calcification, with conflicting results (29-32). Using data from the Mul- tiethnic Study of Atherosclerosis (MESA), a large, population-based study of the determinants of subclinical atherosclerosis, we investigated cross-sectional associations of 4 psychosocial measures (anger, anxiety, depression, and chronic stress burden) with coronary calcification in a large sample of adults, 45 to 84 years of age, with no history of clinical cardiovascular disease. We hypothesized that depression, anxiety, anger, and chronic stress burden would be positively associated with the prevalence of calcification and with the amount of calcium, independent of established cardiovascular risk factors.

\section{Methods}

The MESA is a longitudinal study supported by the National Heart, Lung, and Blood Institute (NHLBI); its goal is identifying risk factors for subclinical atherosclero-

See also:

Print

Editors' Notes . . . . . . . . . . . . . . . . . . . . . . . . 823

Editorial comment. . . . . . . . . . . . . . . . . . . . 858

Summary for Patients. . . . . . . . . . . . . . . . . I-28

Web-Only

Conversion of figure and tables into slides 
Psychosocial Factors and Coronary Calcium in Adults ARTICLE

sis. Details of the study design have been published elsewhere (33). Between July 2000 and August 2002, 6814 men and women 45 to 84 years of age who identified themselves as white, black, Hispanic, or Chinese and were free of clinically apparent cardiovascular disease were recruited from 6 U.S. communities: Baltimore City and Baltimore County, Maryland; Chicago, Illinois; Forsyth County, North Carolina; Los Angeles County, California; Northern Manhattan and the Bronx, New York; and St. Paul, Minnesota. Each field site recruited participants from locally available sources, which included lists of residents, lists of dwellings, and telephone exchanges. In the last few months of the recruitment period, supplemental sources, such as lists of Medicare beneficiaries from the Centers for Medicare \& Medicaid Services and referrals by participants, were used to ensure adequate numbers of minority and elderly participants. The age distribution of the final sample was as follows: 45 to 54 years (27\%), 55 to 64 years (28\%), 65 to 74 years (30\%), and 75 years or older $(16 \%)$. Percentages do not sum to 100 because of rounding. Coronary calcium was assessed by using chest computed tomography $(\mathrm{CT})$ with a cardiac-gated electron-beam CT scanner (34) (Chicago, Los Angeles, and New York field centers) or a multidetector CT system (35) (Baltimore, Forsyth County, and St. Paul field centers) (36). All participants had scanning over phantoms of known physical calcium concentration. A cardiologist read all scans at the Harbor-UCLA Research and Education Institute in Torrance, California, to identify and quantify coronary calcification, calibrated according to the readings of the calcium phantom. Scans were read blindly with respect to scan pairs and to other participant data by using a computerized interactive scoring system similar to that described by Yaghoubi and colleagues (37). The score of Agatston and colleagues (38) was used in all analyses. The Agatston score and the volumetric calcium score were very highly correlated in this sample $(r=0.99)$. The presence of calcification was defined as an average Agatston score greater than 0 .

Psychosocial factors were assessed by using standardized questionnaires written in English, Spanish, or Chinese. Depression was assessed by using the Center for Epidemiology Studies-Depression (CES-D) scale (39), anger and anxiety were assessed by using the Spielberger trait anger and the Spielberger trait anxiety scales (40), and chronic psychological stress was assessed by using the chronic burden scale (41). The Spielberger trait anger scale, the Spielberger trait anxiety scale, and the CES-D have been used extensively in community samples and were scored according to standard criteria, with possible ranges of 10 to 40 for trait anger, 10 to 40 for trait anxiety, and 0 to 60 for CES-D; higher scores indicated higher levels of anger, anxiety, and depressive symptoms, respectively. Scores were analyzed as continuous variables and were categorized into 4 groups according to quartiles of the full distribution. The CES-D score was also dichotomized into scores of 16 or greater (often used as a screening cutoff for

\section{Context}

The role of psychosocial risk factors in the pathogenesis of coronary heart disease (CHD) is difficult to ascertain after patients develop CHD symptoms.

\section{Contribution}

The authors administered standardized questionnaires about psychosocial factors and did electron-beam chest computed tomography in a community-based sample of 6814 adults without CHD symptoms. The prevalence of coronary calcium varied from approximately $35 \%$ to approximately $70 \%$ by race and ethnicity and sex. Psychosocial factors were not associated with coronary artery calcium scores.

\section{Cautions}

The study used 1-time measurement of psychosocial factors, whose effects are probably cumulative.

\section{Implications}

The results make it less likely that psychosocial factors are a contributing cause of CHD.

- The Editors

depression) and scores less than 16. The Spielberger trait anger and anxiety scales were designed to measure relatively stable individual differences (traits as opposed to states). In responding to the CES-D, participants are asked to refer to the way they have felt during the past week. The chronic burden scale (41) consists of 5 items that ask participants to report ongoing difficulties in 5 domains: health of self, health of others, job or ability to work, finances, and relationships. Participants were coded as having a difficulty in the domain in question if they reported a moderately stressful or severely stressful ongoing problem that had been present for 6 months or more. The chronic burden score was the number of items for which participants reported an ongoing difficulty (range, 1 to 5). Participants were classified into 3 groups $(0,1$, and $\geq 2$ ongoing difficulties) for analyses. We also investigated anger, anxiety, and depression jointly by constructing a cumulative score of negative affectivity (42). This cumulative score was constructed by assigning a separate score of 0 to 3 to quartiles of the anger, anxiety, and depression measures separately and summing across the 3 measures.

Information on sociodemographic indicators and cardiovascular risk factors was obtained from the MESA baseline questionnaire. Race and ethnicity were characterized on the basis of participants' responses to questions modeled on the 2000 U.S. Census. Family annual income and education were each classified into 3 groups $(<\$ 20000$, $\$ 20000$ to $\$ 49999$, and $\geq \$ 50000$ and less than high school; completed high school, technical school certificate or associate degree; and completed college or more). Cardiovascular risk factors (smoking history, body mass index 
ARTICLE 1 Psychosocial Factors and Coronary Calcium in Adults

Table 1. Distribution of Psychosocial Measures and Coronary Calcification by Race and Ethnicity and Sex in the Multiethnic Study of Atherosclerosis, 2000-2002*

\begin{tabular}{|c|c|c|c|c|c|c|c|c|}
\hline \multirow[t]{2}{*}{ Variable } & \multicolumn{2}{|c|}{$\begin{array}{l}\text { Non-Hispanic White } \\
\text { Participants }\end{array}$} & \multicolumn{2}{|c|}{$\begin{array}{l}\text { Non-Hispanic African- } \\
\text { American Participants }\end{array}$} & \multicolumn{2}{|c|}{ Hispanic Participants } & \multicolumn{2}{|c|}{ Chinese Participants } \\
\hline & $\begin{array}{l}\text { Men } \\
(n=1256)\end{array}$ & $\begin{array}{l}\text { Women } \\
(n=1360)\end{array}$ & $\begin{array}{l}\text { Men } \\
(n=838)\end{array}$ & $\begin{array}{l}\text { Women } \\
(n=1040)\end{array}$ & $\begin{array}{l}\text { Men } \\
(n=718)\end{array}$ & $\begin{array}{l}\text { Women } \\
(n=774)\end{array}$ & $\begin{array}{l}\text { Men } \\
(n=390)\end{array}$ & $\begin{array}{l}\text { Women } \\
(n=413)\end{array}$ \\
\hline Mean anger score (SD) & $14.8(3.3)$ & $14.9(3.5)$ & $14.0(3.3)$ & $14.3(3.4)$ & $14.8(4.3)$ & $15.1(4.2)$ & $15.5(3.8)$ & $15.3(3.7)$ \\
\hline Mean anxiety score (SD) & $15.4(4.2)$ & $16.8(4.7)$ & $14.5(4.0)$ & $15.7(4.3)$ & $15.6(4.8)$ & $16.6(4.7)$ & $15.9(4.1)$ & $16.7(4.7)$ \\
\hline Mean depression score (SD) & $6.1(6.3)$ & $7.9(7.6)$ & $6.1(6.2)$ & $8.4(7.9)$ & $7.8(7.7)$ & $11.1(9.7)$ & $5.4(5.6)$ & $7.1(7.2)$ \\
\hline $\begin{array}{l}\text { Mean chronic burden score (SD) } \\
\text { Distribution, \%† }\end{array}$ & $0.75(0.96)$ & $1.13(1.16)$ & $0.76(1.07)$ & $1.15(1.21)$ & $0.74(1.06)$ & $0.93(1.10)$ & $0.40(0.75)$ & $0.57(0.96)$ \\
\hline None & 51.7 & 36.5 & 56.3 & 39.3 & 57.3 & 45.0 & 72.2 & 66.2 \\
\hline 1 & 29.8 & 31.9 & 23.5 & 27.3 & 23.7 & 30.7 & 18.8 & 18.3 \\
\hline 2 or more & 18.5 & 31.6 & 20.2 & 33.4 & 19.0 & 24.3 & 9.0 & 15.6 \\
\hline $\begin{array}{c}\text { Prevalence of coronary } \\
\text { calcification, \% }\end{array}$ & 70.4 & 44.7 & 52.1 & 36.6 & 56.5 & 34.8 & 59.2 & 41.9 \\
\hline $\begin{array}{l}\text { Median Agatston score in } \\
\text { participants with } \\
\text { calcification (25th-75th } \\
\text { percentile) }\end{array}$ & $\begin{array}{l}162 \\
(33-468)\end{array}$ & $\begin{array}{l}74 \\
(17-245)\end{array}$ & $\begin{array}{l}81 \\
(25-303)\end{array}$ & $\begin{array}{l}58 \\
(17-194)\end{array}$ & $\begin{array}{l}92 \\
(26-349)\end{array}$ & $\begin{array}{l}46 \\
(14-150)\end{array}$ & $\begin{array}{l}85 \\
(23-233)\end{array}$ & $\begin{array}{l}53 \\
(19-153)\end{array}$ \\
\hline
\end{tabular}

* Scales have possible ranges of 10 to 40 for trait anxiety, 10 to 40 for trait anger, and 0 to 60 for Center for Epidemiology Studies-Depression, with higher scores indicating higher levels of anxiety, anger, and depressive symptoms, respectively. The chronic burden scale is the number of items (out of 5) for which participants reported a moderately or very stressful problem that had been ongoing for 6 months or more. The number of participants for whom data on anger, anxiety, depression, and chronic burden were available was $6782,6775,6778$, and 6665 , respectively.

t Refers to number of very stressful ongoing problems lasting 6 months or more.

[BMI], low-density lipoprotein [LDL] and high-density lipoprotein [HDL] cholesterol levels, hypertension [43], and diabetes [44]) were assessed as part of the baseline examination. Body mass index was calculated as weight in kilograms divided by the square of height in meters. Resting blood pressure was measured 3 times with a Dinamap model Pro 1000 automated oscillometric sphygmomanometer (Critikon, Tampa, Florida) with participants in the seated position. The average of the last 2 measurements was used in the analysis. High-density lipoprotein cholesterol and glucose levels were measured from blood samples obtained after a 12-hour fast. Low-density lipoprotein cholesterol level was calculated with the equation of Friedewald and colleagues (45). Diabetes was defined as a fasting glucose level greater than $6.99 \mathrm{mmol} / \mathrm{L}(>126 \mathrm{mg} / \mathrm{dL})$ or use of hypoglycemic medication.

\section{Statistical Analysis}

The internal consistency of the psychosocial scales was investigated by estimating Cronbach $\alpha$ coefficients. Because the predictors of having any coronary calcification may be different from the predictors of the amount of calcium in persons with calcification, we modeled the presence and amount of calcium in separate analyses. We used relative risk regression to directly estimate prevalence ratios of coronary calcification associated with the exposures of interest. Relative prevalences can be derived from binomial regression models fitted by using Proc Genmod in SAS (SAS Institute, Inc., Cary, North Carolina) $(46,47)$. Because the use of a binomial error resulted in convergence problems, a Gaussian error was used (48). To avoid underestimation of standard errors, robust standard errors (49) were estimated by using the Proc Genmod repeated state- ment in SAS (47). When a Gaussian error model with a log link is used, estimated prevalences falling below 0 or increasing above 1 may result. In our log-link Gaussian error models, we found that up to $4.8 \%$ of the estimated prevalences in men and up to $2.4 \%$ of the estimated prevalences in women were outside this range. Because of these nonvalid prevalence estimates, this model is generally not preferred over standard models, such as logistic regression. We therefore ran additional logistic regression analyses as a sensitivity check and found our conclusions to be qualitatively similar. Results were also virtually identical when Poisson regression (50) was used. Analyses of the amount of calcium among persons with calcium modeled the logarithm of the Agatston score as a function of covariates using linear regression. Exponentiated coefficients from these models can be interpreted as relative differences in the amount of calcium associated with the variable of interest. To model the associations of interest across the range of coronary calcium values in a single model, we repeated selected analyses using Tobit regression and ordinal logistic regression (51). Calcium was categorized into 5 levels: no calcium and 4 categories based on approximate quartiles of the sex-specific calcium distribution.

There was no evidence of interactions of sex or race and ethnicity with the psychosocial measures studied $(P>$ 0.1 for all tests for interactions); however, all results are stratified by sex because of large sex differences in the prevalence of coronary calcification. Models were re-run after additional adjustment for socioeconomic characteristics and cardiovascular risk factors. Heterogeneity of associations by age, income, and site were tested by including interaction terms in regression models. All reported $P$ val- 
ues correspond to 2-tailed tests. The institutional review boards at University of California, Los Angeles, Johns Hopkins University, University of Minnesota, Northwestern University, Columbia University, and Wake Forest University approved the study. All participants gave written informed consent.

\section{Role of the Funding Source}

The MESA is funded by the NHLBI. Together with MESA investigators, NHLBI staff participated in the design of the study and monitored study performance. The NHLBI also comments on manuscripts that result from contract support but does not provide official approval or disapproval.

\section{RESULTS}

Of all 6814 MESA participants, 25 were excluded because of missing information on the 4 psychosocial measures of interest, leaving 6789 participants for analysis. Table 1 shows the distribution of anger, anxiety, depression, and chronic burden scores by race and ethnicity and sex.
For all variables except anger, mean scores were significantly higher $(P<0.001)$ in women than in men. There were no consistent patterns in mean scores by race and ethnicity. As previously reported for the MESA sample, the proportion of persons with calcification and the amount of calcium in those with calcification differed by race and ethnicity (52). Cronbach $\alpha$ coefficients by sex and race suggest that the internal consistency of the 3 standard scales is acceptably high and is stable across sex and race and ethnicity, ranging from a low of 0.72 for depression in Chinese persons and white men to a high of 0.84 for anger in Hispanic men (not shown in Table 1).

Table 2 shows the distribution of selected demographic, behavioral, and biological characteristics by categories of psychosocial measures. Mean age decreased across categories of increasing levels of psychosocial measures. Higher levels of anxiety, chronic burden, and depression were associated with lower income, but no clear socioeconomic differences were observed for anger. Higher levels of psychosocial measures were positively associated with

\section{Table 2. Selected Demographic, Behavioral, and Biological Characteristics by Categories of Psychosocial Measures in the Multiethnic Study of Atherosclerosis, 2000-2002*}

Variable

$\begin{array}{lll}\text { Median } & \text { Mean } & \text { Women, } \\ \text { Score } & \text { Age, } y & \%\end{array}$

$\begin{array}{ll}\text { Annual } & \text { Current } \\ \text { Income } & \text { Smokers, } \\ <\$ 25000, & \%\end{array}$
$<\$ 25000$

$\begin{array}{lll}\text { Participants } & \text { Participants } & \begin{array}{l}\text { Mean Body } \\ \text { with }\end{array} \\ \begin{array}{l}\text { wyth } \\ \text { Hypertension, }\end{array} & \begin{array}{l}\text { Diabetes, } \\ \%\end{array} & \mathrm{~kg} / \mathrm{m}^{2} \\ & \% & \end{array}$

$\begin{array}{ll}65.0 & 51.7 \\ 62.5 & 53.7 \\ 60.9 & 52.3 \\ 59.5 & 53.8 \\ <0.001 & \end{array}$

$\begin{array}{ll}51.7 & 27 \\ 53.7 & 27 . \\ 52.3 & 26 . \\ 53.8 & 29 . \\ 0.50 & \end{array}$

\begin{tabular}{ccc}
27.9 & 9.9 & 42. \\
27.6 & 11.0 & 41. \\
26.7 & 12.2 & 42. \\
29.0 & 13.3 & 47. \\
0.50 & $<0.001$ & 0. \\
\hline
\end{tabular}

$\begin{array}{ccc}42.4 & 12.2 & 27.60 \\ 41.2 & 11.3 & 27.87 \\ 42.9 & 13.4 & 27.83 \\ 47.2 & 13.8 & 27.96 \\ 0.005 & 0.113 & 0.044\end{array}$

Anxiety
Group 1 (lowest)
Group 2
Group 3
Group 4 (highest)
P value for trend
across groupst

$\begin{array}{lll}11 & 63.8 & 4 \\ 14 & 62.2 & 49 . \\ 17 & 61.1 & 56 . \\ 21 & 61.3 & 61 . \\ & <0.001\end{array}$

$\begin{array}{ll}45.4 & 23 . \\ 49.1 & 24 . \\ 56.0 & 27 . \\ 61.3 & 35 . \\ <0.001 & <0 .\end{array}$

$\begin{array}{lll}23.9 & 10.5 & 41 . \\ 24.3 & 10.3 & 41 . \\ 27.2 & 12.3 & 4 \\ 35.9 & 13.1 & 47.8 \\ <0.001 & 0.004 & <0 .\end{array}$

$\begin{array}{ll}41.7 & 13 . \\ 41.6 & 1 \\ 42.7 & 12.1 \\ 47.8 & 13.3 \\ <0.001 & \end{array}$

$\begin{array}{cr}13.0 & 27.88 \\ 12.1 & 27.76 \\ 12.1 & 27.57 \\ 13.3 & 27.99 \\ 0.80 & 0.56\end{array}$

\begin{tabular}{|c|c|c|c|c|c|c|c|c|}
\hline \multicolumn{9}{|l|}{ Depression } \\
\hline Group 1 (lowest) & 1 & 62.8 & 46.1 & 22.6 & 9.2 & 42.0 & 11.9 & 27.52 \\
\hline Group 2 & 4 & 62.0 & 47.9 & 23.2 & 10.0 & 43.0 & 12.2 & 27.85 \\
\hline Group 3 & 7 & 62.2 & 53.7 & 26.5 & 12.4 & 42.5 & 12.2 & 27.86 \\
\hline Group 4 (highest) & 16 & 61.5 & 64.0 & 39.3 & 14.4 & 46.5 & 14.3 & 28.04 \\
\hline $\begin{array}{l}P \text { value for trend } \\
\text { across groups }\end{array}$ & & $<0.001$ & $<0.001$ & $<0.001$ & $<0.001$ & 0.012 & 0.025 & 0.007 \\
\hline \multicolumn{9}{|l|}{ Chronic burden } \\
\hline Group 1 (lowest) & 0 & 63.3 & 45.3 & 25.7 & 10.6 & 41.4 & 11.0 & 27.50 \\
\hline Group 2 & 1 & 62.4 & 52.6 & 25.4 & 11.7 & 42.5 & 12.3 & 27.77 \\
\hline Group 3 (highest) & 2 & 59.4 & 60.5 & 34.2 & 13.3 & 49.0 & 16.7 & 28.56 \\
\hline $\begin{array}{l}P \text { value for trend } \\
\text { across groups }\end{array}$ & & $<0.001$ & $<0.001$ & $<0.001$ & 0.005 & $<0.001$ & $<0.001$ & $<0.001$ \\
\hline
\end{tabular}

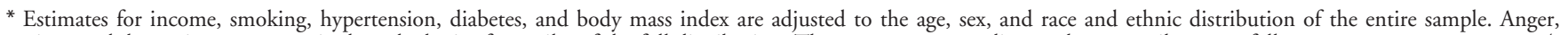

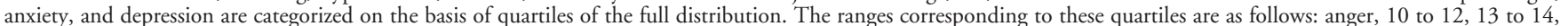

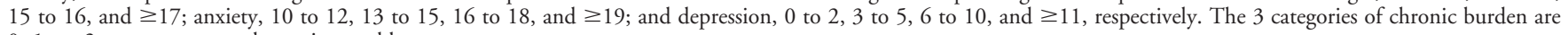
0,1 , or 2 or more reported ongoing problems.

† For the $P$ value for trend for each of the psychosocial variables, an ordinal variable was constructed with the median value of the predictor used as rank value.
} 

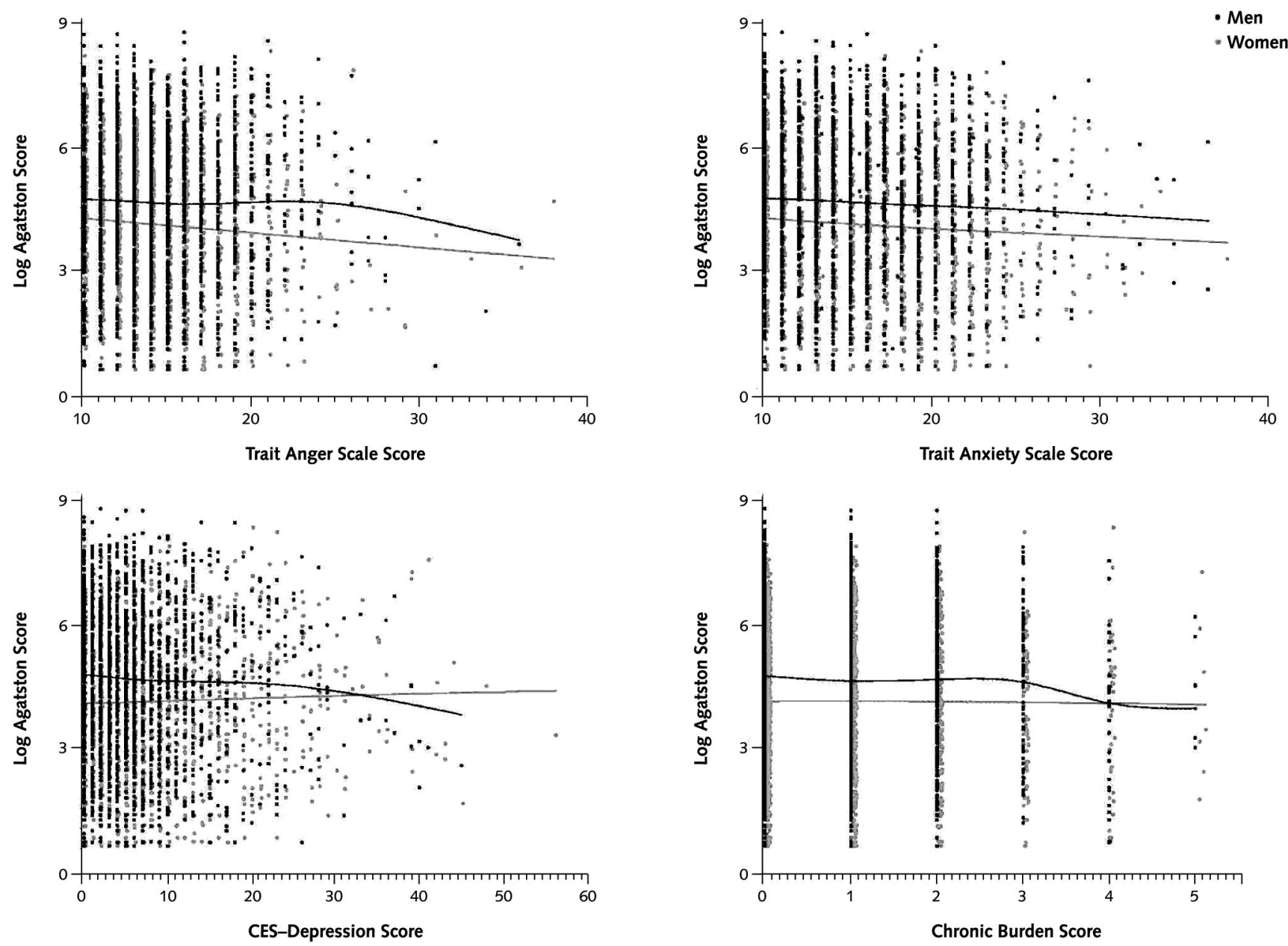

One point was added to all Agatston scores before taking the logarithm so that the 0 score could be included in the figure. Smooth lines were fitted by using a cubic spline (53). Points for women were offset slightly to the right to induce separation between both sexes.

smoking. The percentage of participants with hypertension was higher in the highest quartile than in the other 3 quartiles for each of the psychosocial variables. The prevalence of diabetes was positively associated with chronic burden and depression, and BMI was positively associated with anger, depression, and chronic burden.

The Figure shows Agatston scores by psychosocial measures in men and women. There was no evidence of a positive association or threshold effect for any of the psychosocial measures. In fact, an inverse association was observed between psychosocial factors and coronary calcium score, especially at higher levels of psychosocial measures, although this negative slope was probably influenced by outliers and sparse data. Table 3 shows prevalence ratios of calcification by categories of psychosocial measures before and after adjustment for cardiovascular risk factors. Smoking, blood pressure, diabetes, and LDL cholesterol level were positively associated with the presence of calcification, although the strength and statistical significance varied by sex. Body mass index was positively associated with the presence of calcification in men but not in women (not shown in Table 3).

There was no evidence that higher levels of any of the psychosocial measures were associated with greater prevalence of calcification (Table 3). Higher levels of anger scores were weakly associated with greater prevalence of calcification in women and greater chronic burden was weakly associated with calcification in men, but these patterns disappeared after adjustment for socioeconomic factors and cardiovascular risk factors. No associations were observed when participants with depression were compared with those without depression by using the CES-D cutoff score of 16 (relative prevalences from fully adjusted models, 1.05 [95\% CI, 0.95 to 1.15 ] in men and 0.94 [CI, 0.84 to 1.05 ] in women). No consistent positive interactions were observed for the amount of calcium among per- 
sons with calcifications (Table 4). Tests for interaction did not find evidence of more positive associations in the younger age groups. There was also no evidence of heterogeneity of associations by income or by site (of 40 interactions tested, only 4 were statistically significant at the 0.1 level). No positive associations of psychosocial factors with coronary calcification were observed in Tobit models, in ordinal logistic regression models, or when analyses were restricted to persons at intermediate risk for coronary heart disease based on the Framingham risk score (26) (results not shown).

\section{Discussion}

Depression (or depressive symptoms) and anger have been linked to recurrent events in patients with coronary disease $(4,54-56)$, and depression, anger, and anxiety have been linked to incident coronary events in populationbased samples $(4-8,57)$. Questions remain regarding whether these associations reflect an effect of psychosocial factors on atherogenesis or a triggering of clinical events in persons with underlying disease. By focusing on coronary calcification in an asymptomatic sample, we were able to examine whether psychosocial factors are cross-sectionally associated with early coronary atherosclerosis. The presence of a cross-sectional association would not necessarily imply a causal relation between psychosocial factors and atherogenesis, but it would provide preliminary evidence for such an effect that would need to be confirmed with designs more appropriate for making causal inferences.

We found no evidence of a relationship between any of the psychosocial factors examined and the presence or amount of coronary calcification. Because of the strong

\section{Table 3. Relative Prevalence of Coronary Calcification by Psychosocial Measures in Men and Women in the Multiethnic Study of Atherosclerosis, 2000-2002}

Variable

Prevalence Ratio $(95 \% \mathrm{Cl})$

\begin{tabular}{llll}
\hline $\begin{array}{l}\text { Group 1 } \\
\text { (Lowest) }\end{array}$ & Group 2 & Group 3 & $\begin{array}{l}\text { Group 4 } \\
\text { (Highest) }\end{array}$
\end{tabular}

Men

Anger

Model 1t

Model $2 \ddagger$

Anxiety

Model $1+$

Model 2‡

Depression

Model $1+$

Model $2 \ddagger$

Negative affect score§

Model 1t

Model 2‡

Chronic burden

Model $1+$

Model 2‡

1

$0.97(0.91-1.03)$

$0.93(0.86-1.00)$

$0.98(0.92-1.03)$

$0.98(0.91-1.05)$

$0.95(0.9-1.01)$

$0.94(0.88-1.02)$

$0.94(0.89-1.00)$

$0.92(0.85-0.99)$

$1.03(0.98-1.08)$

$1.02(0.95-1.08)$

$0.96(0.89-1.02)$
$0.92(0.84-0.99)$
$0.96(0.9-1.03)$
$0.96(0.89-1.04)$
$0.97(0.92-1.04)$
$0.99(0.92-1.07)$
$0.99(0.93-1.05)$
$0.98(0.91-1.05)$
$1.05(0.98-1.13)$
$1.02(0.94-1.11)$

$1.02(0.94-1.11)$
(Highest)

$P$ Value for Trend across Groups*

Women

Anger

\begin{tabular}{|c|c|c|c|c|c|}
\hline Model 1† & 1 & $1.04(0.95-1.13)$ & $1.05(0.96-1.15)$ & $1.08(0.98-1.19)$ & 0.094 \\
\hline Model 2‡ & 1 & $1.04(0.94-1.15)$ & $0.95(0.85-1.07)$ & $1.01(0.9-1.15)$ & 0.97 \\
\hline \multicolumn{6}{|l|}{ Anxiety } \\
\hline Model 1† & 1 & $1.02(0.93-1.11)$ & $0.96(0.87-1.06)$ & $0.98(0.89-1.07)$ & 0.42 \\
\hline Model 2‡ & 1 & $1.04(0.93-1.16)$ & $0.98(0.87-1.1)$ & $0.93(0.83-1.05)$ & 0.128 \\
\hline \multicolumn{6}{|l|}{ Depression } \\
\hline Model 1† & 1 & $0.97(0.87-1.07)$ & $1.02(0.93-1.11)$ & $0.98(0.9-1.07)$ & 0.83 \\
\hline Model 2‡ & 1 & $1.00(0.89-1.13)$ & $1.02(0.91-1.14)$ & $0.92(0.82-1.04)$ & 0.101 \\
\hline \multicolumn{6}{|c|}{ Negative affect score§ } \\
\hline Model 1† & 1 & $1.02(0.93-1.12)$ & $1.03(0.95-1.13)$ & $1.01(0.92-1.1)$ & 0.83 \\
\hline Model 2‡ & 1 & $0.96(0.86-1.07)$ & $0.97(0.87-1.08)$ & $0.90(0.80-1.01)$ & 0.075 \\
\hline \multicolumn{6}{|c|}{ Chronic burden } \\
\hline Model 1† & 1 & $1.03(0.95-1.11)$ & $1.00(0.92-1.09)$ & - & 0.87 \\
\hline Model 2‡ & 1 & $1.04(0.95-1.13)$ & $0.88(0.79-0.99)$ & - & 0.088 \\
\hline
\end{tabular}

* For $P$ values for trend, an ordinal variable was constructed with the median value of the predictor used as the rank value.

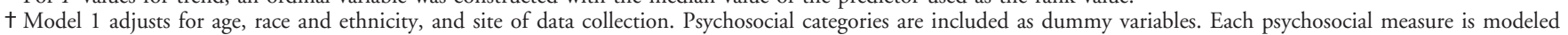
separately.

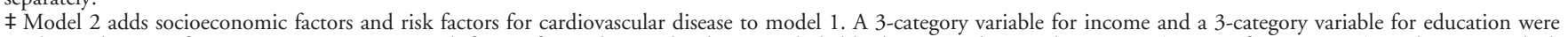

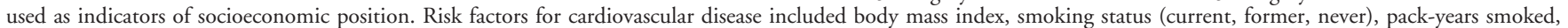

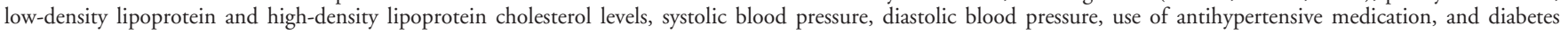
status.

$\S$ The negative affect score combines anger, anxiety, and depression as described in the Methods section. 
association between coronary calcification and incident coronary events (for example, a 50\% increased risk for persons with scores of 1 to 100 compared with those without calcium [26]), even small differences in relative prevalence (for example, $10 \%$ or $15 \%$ ) would imply clinically significant effects. However, even for the highest quartile of psychosocial factors, point estimates were well below these levels, and upper bounds on the estimates rarely approached them. Of the 4 previous studies of psychosocial factors and coronary calcification, 3 focused on the psychosocial dimensions that we examined. O'Malley and colleagues (30) did not find an association between depression, anxiety, or stress and coronary calcification. Tiemeier and colleagues (31) and Agatisa and colleagues (32) found greater odds of coronary calcification associated with depressive disorders or major depression but did not find an association between depressive symptoms and coronary calcification. The sample studied by O'Malley and colleagues (30) consisted of young, mostly white male active-duty military personnel who probably constituted a highly selected group and may have been less likely to report psychosocial symptoms. Agatisa and colleagues (32) studied a small sample of healthy middle-aged women. The largest sample was that studied by Tiemeier and colleagues (31), but it was restricted to persons older than 60 years of age and included symptomatic and asymptomatic persons.

In contrast to previous work, which has focused on small samples or samples restricted in sex or age, we investigated these associations across the continuum of subclinical disease in a large, multiethnic sample of men and women spanning a broad age range. The variability was large in measures of coronary calcification in our sample. With the exception of the chronic burden scale, the psychosocial measures we used were based on well-established and validated scales. In general, mean levels for depressive symptoms, anger, and anxiety were similar to those reported in other population-based samples $(58-60)$. Thus, limited variability in exposure or outcome is unlikely to explain our null findings. We were not able to investigate the role of major depression, but no associations were observed when the CES-D score was dichotomized into scores of 16 or greater (often used as a screening cutoff for depression) and scores less than 16.

Hostility is the psychosocial characteristic most consistently associated with measures of atherosclerosis in previous studies, perhaps in part because it has been one of the most commonly examined measures $(58,61-64)$. Hostility was recently found to be associated with coronary calcification in 1 small study of young adults (29), but O'Malley and colleagues (30) did not find this association in their study of army personnel. A hostility measure will be investigated in subsequent follow-ups of the MESA cohort.

The presence of coronary calcium is 1 of several currently available measures of subclinical atherosclerosis. Although calcium deposits in the coronary arteries indicate the presence of plaque, the absence of calcium does not imply that atherosclerosis is not present (65). There is some evidence that coronary calcification exhibits similarities to bone formation and remodeling (66) and therefore that the amount of coronary calcium depends not only on atherosclerotic burden but also on the balance of hormonal and metabolic factors related to bone formation and tissue calcification. It is plausible that some physiologic correlates of psychosocial stress, such as glucocorticoid levels (67) or inflammatory markers (11), generally are negatively associated with bone formation and calcification (11, 68-70) and could therefore be negatively associated with calcification of atherosclerotic plaques. Thus, the absence of asso-

Table 4. Adjusted Relative Differences in Coronary Calcification Associated with Psychosocial Characteristics among Participants with Detectable Calcification Stratified by Sex in the Multiethnic Study of Atherosclerosis, 2000-2002*

Variable

\begin{tabular}{lllll} 
& \multicolumn{2}{c}{ Adjusted Relative Difference in Coronary Calcium $(95 \% \mathrm{Cl})$} & & $P$ Value for \\
& & & Trend \\
$\begin{array}{l}\text { Group 1 } \\
\text { (Lowest) }\end{array}$ & Group 2 & Group 3 & Group 4 & across \\
(Highest) & Groupst
\end{tabular}

\begin{tabular}{|c|c|c|c|c|c|}
\hline \multicolumn{6}{|l|}{ Men } \\
\hline Anger & 1 & $0.89(0.69-1.14)$ & $0.93(0.7-1.23)$ & $1.01(0.78-1.31)$ & 0.92 \\
\hline Anxiety & 1 & $0.96(0.75-1.22)$ & $0.99(0.75-1.3)$ & $0.81(0.62-1.06)$ & 0.16 \\
\hline Depression & 1 & $0.94(0.73-1.2)$ & $0.8(0.62-1.02)$ & $0.77(0.58-1.01)$ & 0.046 \\
\hline Combined negative affect score‡ & 1 & $0.95(0.74-1.22)$ & $0.99(0.76-1.27)$ & $0.8(0.61-1.05)$ & 0.16 \\
\hline Chronic burden & 1 & $0.83(0.67-1.04)$ & $0.88(0.67-1.16)$ & - & 0.18 \\
\hline \multicolumn{6}{|l|}{ Women } \\
\hline Anger & 1 & $1.04(0.78-1.39)$ & $1.14(0.83-1.58)$ & $1.03(0.76-1.41)$ & 0.80 \\
\hline Anxiety & 1 & $1.16(0.85-1.59)$ & $1.1(0.79-1.52)$ & $0.83(0.6-1.13)$ & 0.136 \\
\hline Depression & 1 & $0.91(0.66-1.24)$ & $0.92(0.68-1.25)$ & $1.14(0.83-1.56)$ & 0.26 \\
\hline Combined negative affect scoreł & 1 & $0.84(0.62-1.14)$ & $1.14(0.84-1.55)$ & $0.93(0.68-1.27)$ & 0.86 \\
\hline Chronic burden & 1 & $1.03(0.79-1.33)$ & $1.03(0.77-1.38)$ & - & 0.81 \\
\hline
\end{tabular}

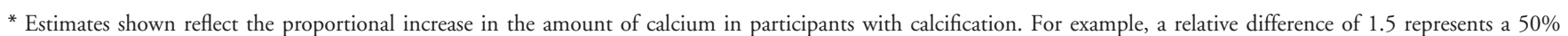
increase in the Agatston score. All estimates are adjusted for age, race and ethnicity, site, income, education, and cardiovascular risk factors (see model 2 in Table 3 ).

† For $P$ value for trend, an ordinal variable was constructed with the median value of the predictor used as the rank value.

₹ The negative affect score combines anger, anxiety, and depression as described in the Methods section. 
Psychosocial Factors and Coronary Calcium in Adults ARTICLE

ciations of psychosocial factors with coronary calcification does not completely rule out associations with early atherosclerosis. Future analyses of the MESA cohort focusing on other subclinical measures may help clarify whether this is the case.

If psychosocial factors are causally related to atherogenesis, effects must occur over long periods. Thus, crosssectional analyses relating current psychosocial characteristics to the existing level of calcification may fail to detect a relationship if current levels are a poor proxy for cumulative exposure to these factors, or if it is change in psychosocial characteristics rather than absolute levels that is relevant for atherosclerosis. Limited evidence shows that some psychosocial factors are relatively stable over time (29, 58, $71,72)$. The Spielberger trait anger and trait anxiety scales were specifically designed to measure relatively stable individual attributes (40). Preliminary data from MESA suggest that all of the psychosocial measures we examined are relatively stable over time (3-year test-retest correlations ranged from 0.56 to 0.63 ). If variability in psychosocial attributes is substantial over time, studies that use a single measure to characterize long-term exposure could be biased toward the null. In contrast, single, recent measures may yield unbiased estimates of the effects of recent exposures as triggers of events, hence the greater consistency of associations observed with clinical outcomes.

Although our sample represented a broad age range, it was weighted toward the older age groups, resulting in a high overall prevalence of calcification. Associations of psychosocial factors with atherosclerosis may be more difficult to detect in situations where the disease is ubiquitous. If psychosocial factors are related to both the development of atherosclerosis and the precipitation of clinical events, cross-sectional analyses of asymptomatic persons (especially at older ages) may be biased toward the null. Stronger associations of psychosocial factors with coronary atherosclerosis in younger rather than in older persons have been previously reported (73). However, we did not find any evidence of stronger associations in the younger age groups in our sample.

Anger, anxiety, depression, and chronic stress burden were not related to coronary calcification in this large, multiethnic sample of asymptomatic adults. Although our results do not disprove the presence of a causal relationship between psychosocial factors and atherosclerosis, they do not support this hypothesis. As follow-up of the MESA cohort continues, it will be possible to examine associations of psychosocial factors with other measures of subclinical atherosclerosis and the role of such factors in precipitating clinical events in persons with varying levels of subclinical disease.

From University of Michigan, Ann Arbor, Michigan; Rush University Medical Center, Chicago, Illinois; Wake Forest University School of Medicine, Winston-Salem, North Carolina; Columbia University, New York, New York; and National Institutes of Health, Bethesda, Maryland.
Note: Drs. Diez Roux and Ranjit had full access to all of the data in the study and take responsibility for the integrity of the data and the accuracy of the data analysis. A full list of participating MESA investigators and institutions can be found at www.mesa-nhlbi.org.

Acknowledgments: The authors thank the other investigators, the staff, and the participants of MESA for their valuable contributions, and Sarah Burgard for assistance with initial data analyses.

Grant Support: By the National Heart, Lung, and Blood Institute (contracts N01-HC-95159 through N01-HC-95165 and N01-HC-95169) (Multiethnic Study of Atherosclerosis) and in part by R01 HL076831 (Dr. Diez Roux).

Potential Financial Conflicts of Interest: None disclosed.

Requests for Single Reprints: Ana V. Diez Roux, MD, PhD, Department of Epidemiology, School of Public Health, University of Michigan, 1214 South University, 2nd Floor, Ann Arbor, MI 48103; e-mail, adiezrou@umich.edu.

Current author addresses and author contributions are available at www .annals.org.

\section{References}

1. Krantz DS, McCeney MK. Effects of psychological and social factors on organic disease: a critical assessment of research on coronary heart disease. Annu Rev Psychol. 2002;53:341-69. [PMID: 11752489]

2. Angell M. Disease as a reflection of the psyche [Editorial]. N Engl J Med. 1985;312:1570-2. [PMID: 4000189]

3. Scheidt $S$. The current status of heart-mind relationships [Editorial]. J Psychosom Res. 2000;48:317-20. [PMID: 10880653]

4. Hemingway H, Marmot M. Evidence based cardiology: psychosocial factors in the aetiology and prognosis of coronary heart disease. Systematic review of prospective cohort studies. BMJ. 1999;318:1460-7. [PMID: 10346775]

5. Wulsin LR, Singal BM. Do depressive symptoms increase the risk for the onset of coronary disease? A systematic quantitative review. Psychosom Med. 2003;65:201-10. [PMID: 12651987]

6. Kawachi I, Sparrow D, Vokonas PS, Weiss ST. Symptoms of anxiety and risk of coronary heart disease. The Normative Aging Study. Circulation. 1994;90: 2225-9. [PMID: 7955177]

7. Kawachi I, Sparrow D, Spiro A 3rd, Vokonas P, Weiss ST. A prospective study of anger and coronary heart disease. The Normative Aging Study. Circulation. 1996;94:2090-5. [PMID: 8901656]

8. Rugulies R. Depression as a predictor for coronary heart disease. A review and meta-analysis. Am J Prev Med. 2002;23:51-61. [PMID: 12093424]

9. Kop WJ, Gottdiener JS, Tangen CM, Fried LP, McBurnie MA, Walston J, et al. Inflammation and coagulation factors in persons $>65$ years of age with symptoms of depression but without evidence of myocardial ischemia. Am J Cardiol. 2002;89:419-24. [PMID: 11835923]

10. Suarez EC, Lewis JG, Kuhn C. The relation of aggression, hostility, and anger to lipopolysaccharide-stimulated tumor necrosis factor (TNF)-alpha by blood monocytes from normal men. Brain Behav Immun. 2002;16:675-84. [PMID: 12480498]

11. Papanicolaou DA, Wilder RL, Manolagas SC, Chrousos GP. The pathophysiologic roles of interleukin-6 in human disease. Ann Intern Med. 1998;128: 127-37. [PMID: 9441573]

12. Frimerman A, Miller HI, Laniado S, Keren G. Changes in hemostatic function at times of cyclic variation in occupational stress. Am J Cardiol. 1997; 79:72-5. [PMID: 9024741]

13. Strike PC, Steptoe A. Psychosocial factors in the development of coronary artery disease. Prog Cardiovasc Dis. 2004;46:337-47. [PMID: 14961456]

14. Guyll M, Contrada RJ. Trait hostility and ambulatory cardiovascular activity: responses to social interaction. Health Psychol. 1998;17:30-9. [PMID: 9459067] 15. Finney ML, Stoney CM, Engebretson TO. Hostility and anger expression in African American and European American men is associated with cardiovascular 
and lipid reactivity. Psychophysiology. 2002;39:340-9. [PMID: 12212653] 16. Skantze HB, Kaplan J, Pettersson K, Manuck S, Blomqvist N, Kyes R, et al. Psychosocial stress causes endothelial injury in cynomolgus monkeys via beta1adrenoceptor activation. Atherosclerosis. 1998;136:153-61. [PMID: 9544742] 17. Ghiadoni L, Donald AE, Cropley M, Mullen MJ, Oakley G, Taylor M, et al. Mental stress induces transient endothelial dysfunction in humans. Circulation. 2000;102:2473-8. [PMID: 11076819]

18. Rajagopalan S, Brook R, Rubenfire M, Pitt E, Young E, Pitt B. Abnormal brachial artery flow-mediated vasodilation in young adults with major depression. Am J Cardiol. 2001;88:196-8, A7. [PMID: 11448425]

19. Markovitz JH. Hostility is associated with increased platelet activation in coronary heart disease. Psychosom Med. 1998;60:586-91. [PMID: 9773762] 20. Musselman DL, Tomer A, Manatunga AK, Knight BT, Porter MR, Kasey $\mathrm{S}$, et al. Exaggerated platelet reactivity in major depression. Am J Psychiatry. 1996;153:1313-7. [PMID: 8831440]

21. Shimbo D, Child J, Davidson K, Geer E, Osende JI, Reddy S, et al. Exaggerated serotonin-mediated platelet reactivity as a possible link in depression and acute coronary syndromes. Am J Cardiol. 2002;89:331-3. [PMID: 11809437]

22. Stein PK, Carney RM, Freedland KE, Skala JA, Jaffe AS, Kleiger RE, et al. Severe depression is associated with markedly reduced heart rate variability in patients with stable coronary heart disease. J Psychosom Res. 2000;48:493-500. [PMID: 10880671]

23. Kawachi I, Sparrow D, Vokonas PS, Weiss ST. Decreased heart rate variability in men with phobic anxiety (data from the Normative Aging Study). Am J Cardiol. 1995;75:882-5. [PMID: 7732994]

24. Björntorp P. Do stress reactions cause abdominal obesity and comorbidities? Obes Rev. 2001;2:73-86. [PMID: 12119665]

25. Rozanski A, Blumenthal JA, Kaplan J. Impact of psychological factors on the pathogenesis of cardiovascular disease and implications for therapy. Circulation. 1999;99:2192-217. [PMID: 10217662]

26. Greenland P, LaBree L, Azen SP, Doherty TM, Detrano RC. Coronary artery calcium score combined with Framingham score for risk prediction in asymptomatic individuals. JAMA. 2004;291:210-5. [PMID: 14722147]

27. Arad Y, Spadaro LA, Goodman K, Newstein D, Guerci AD. Prediction of coronary events with electron beam computed tomography. J Am Coll Cardiol. 2000;36:1253-60. [PMID: 11028480]

28. O'Malley PG, Taylor AJ, Jackson JL, Doherty TM, Detrano RC. Prognostic value of coronary electron-beam computed tomography for coronary heart disease events in asymptomatic populations. Am J Cardiol. 2000;85:945-8. [PMID: 10760331]

29. Iribarren C, Sidney S, Bild DE, Liu K, Markovitz JH, Roseman JM, et al. Association of hostility with coronary artery calcification in young adults: the CARDIA study. Coronary Artery Risk Development in Young Adults. JAMA. 2000;283:2546-51. [PMID: 10815118]

30. O'Malley PG, Jones DL, Feuerstein IM, Taylor AJ. Lack of correlation between psychological factors and subclinical coronary artery disease. $\mathrm{N}$ Engl J Med. 2000;343:1298-304. [PMID: 11058674]

31. Tiemeier H, van Dijck W, Hofman A, Witteman JC, Stijnen T, Breteler MM. Relationship between atherosclerosis and late-life depression: the Rotterdam Study. Arch Gen Psychiatry. 2004;61:369-76. [PMID: 15066895]

32. Agatisa PK, Matthews KA, Bromberger JT, Edmundowicz D, Chang YF, Sutton-Tyrrell K. Coronary and aortic calcification in women with a history of major depression. Arch Intern Med. 2005;165:1229-36. [PMID: 15956001]

33. Bild DE, Bluemke DA, Burke GL, Detrano R, Diez Roux AV, Folsom AR, et al. Multi-ethnic study of atherosclerosis: objectives and design. Am J Epidemiol. 2002;156:871-81. [PMID: 12397006]

34. Breen JF, Sheedy PF 2nd, Schwartz RS, Stanson AW, Kaufmann RB, Moll PP, et al. Coronary artery calcification detected with ultrafast $\mathrm{CT}$ as an indication of coronary artery disease. Radiology. 1992;185:435-9. [PMID: 1410350]

35. Carr JJ, Crouse JR 3rd, Goff DC Jr, D’Agostino RB Jr, Peterson NP, Burke GL. Evaluation of subsecond gated helical CT for quantification of coronary artery calcium and comparison with electron beam CT. AJR Am J Roentgenol. 2000;174:915-21. [PMID: 10749222]

36. Carr JJ, Nelson JC, Wong ND, McNitt-Gray M, Arad Y, Jacobs DR Jr, et al. Calcified coronary artery plaque measurement with cardiac CT in populationbased studies: standardized protocol of Multi-Ethnic Study of Atherosclerosis (MESA) and Coronary Artery Risk Development in Young Adults (CARDIA) study. Radiology. 2005;234:35-43. [PMID: 15618373]

37. Yaghoubi S, Tang W, Wang S, Reed J, Hsiai J, Detrano R, et al. Offline assessment of atherosclerotic coronary calcium from electron beam tomograms. Am J Card Imaging. 1995;9:231-6. [PMID: 8680138]

38. Agatston AS, Janowitz WR, Hildner FJ, Zusmer NR, Viamonte M Jr, Detrano R. Quantification of coronary artery calcium using ultrafast computed tomography. J Am Coll Cardiol. 1990;15:827-32. [PMID: 2407762]

39. Radloff LS. The CES-D Scale. A self-report depression scale for research in the general population. Applied Psychological Measurement. 1977;1:385-401. 40. Spielberger CD. Preliminary Manual for the State-Trait Personality Inventory. Palo Alto, CA: Consulting Psychologist Pr; 1980.

41. Bromberger JT, Matthews KA. A longitudinal study of the effects of pessimism, trait anxiety, and life stress on depressive symptoms in middle-aged women. Psychol Aging. 1996;11:207-13. [PMID: 8795049]

42. Denollet J, Brutsaert DL. Personality, disease severity, and the risk of longterm cardiac events in patients with a decreased ejection fraction after myocardial infarction. Circulation. 1998;97:167-73. [PMID: 9445169]

43. The sixth report of the Joint National Committee on prevention, detection, evaluation, and treatment of high blood pressure. Arch Intern Med. 1997;157: 2413-46. [PMID: 9385294]

44. Report of the Expert Committee on the Diagnosis and Classification of Diabetes Mellitus. Diabetes Care. 1997;20:1183-97. [PMID: 9203460]

45. Friedewald WT, Levy RI, Fredrickson DS. Estimation of the concentration of low-density lipoprotein cholesterol in plasma, without use of the preparative ultracentrifuge. Clin Chem. 1972;18:499-502. [PMID: 4337382]

46. Robbins AS, Chao SY, Fonseca VP. What's the relative risk? A method to directly estimate risk ratios in cohort studies of common outcomes. Ann Epidemiol. 2002;12:452-4. [PMID: 12377421]

47. SAS Institute, Inc. SAS/STAT, version 9.1 User's Guide. Cary, NC: SAS Institute; 2004.

48. Lumley T, Diehr P, Emerson S, Chen L. The importance of the normality assumption in large public health data sets. Annu Rev Public Health. 2002;23: 151-69. [PMID: 11910059]

49. Royall RM. Model robust inference using maximum likelihood estimators. Int Stat Rev. 1986;54:221-6.

50. Zou G. A modified poisson regression approach to prospective studies with binary data. Am J Epidemiol. 2004;159:702-6. [PMID: 15033648]

51. Reilly MP, Wolfe ML, Localio AR, Rader DJ. Coronary artery calcification and cardiovascular risk factors: impact of the analytic approach. Atherosclerosis. 2004;173:69-78. [PMID: 15177125]

52. Bild DE, Detrano R, Peterson D, Guerci A, Liu K, Shahar E, et al. Ethnic differences in coronary calcification: the Multi-Ethnic Study of Atherosclerosis (MESA). Circulation. 2005;111:1313-20. [PMID: 15769774]

53. Reinsch $\mathrm{CH}$. Smoothing by spline functions. Numerische Mathematik. 1967;10:177-83.

54. Frasure-Smith N, Lespérance F, Talajic M. Depression following myocardial infarction. Impact on 6-month survival. JAMA. 1993;270:1819-25. [PMID: 8411525]

55. Mendes de Leon CF, Kop WJ, de Swart HB, Bär FW, Appels AP. Psychosocial characteristics and recurrent events after percutaneous transluminal coronary angioplasty. Am J Cardiol. 1996;77:252-5. [PMID: 8607403]

56. Mittleman MA, Maclure M, Sherwood JB, Mulry RP, Tofler GH, Jacobs $\mathrm{SC}$, et al. Triggering of acute myocardial infarction onset by episodes of anger. Determinants of Myocardial Infarction Onset Study Investigators. Circulation. 1995;92:1720-5. [PMID: 7671353]

57. Everson SA, Goldberg DE, Kaplan GA, Cohen RD, Pukkala E, Tuomilehto J, et al. Hopelessness and risk of mortality and incidence of myocardial infarction and cancer. Psychosom Med. 1996;58:113-21. [PMID: 8849626] 58. Matthews KA, Owens JF, Kuller LH, Sutton-Tyrrell K, Jansen-McWilliams L. Are hostility and anxiety associated with carotid atherosclerosis in healthy postmenopausal women? Psychosom Med. 1998;60:633-8. [PMID: 9773770]

59. Williams JE, Nieto FJ, Sanford CP, Couper DJ, Tyroler HA. The association between trait anger and incident stroke risk: the Atherosclerosis Risk in Communities (ARIC) Study. Stroke. 2002;33:13-9. [PMID: 11779882]

60. Ferketich AK, Schwartzbaum JA, Frid DJ, Moeschberger ML. Depression as an antecedent to heart disease among women and men in the NHANES I study. National Health and Nutrition Examination Survey. Arch Intern Med. 2000;160:1261-8. [PMID: 10809028]

61. Williams RB Jr, Haney TL, Lee KL, Kong YH, Blumenthal JA, Whalen RE. Type A behavior, hostility, and coronary atherosclerosis. Psychosom Med. 1980;42:539-49. [PMID: 7465739] 
62. Barefoot JC, Patterson JC, Haney TL, Cayton TG, Hickman JR Jr, Williams RB. Hostility in asymptomatic men with angiographically confirmed coronary artery disease. Am J Cardiol. 1994;74:439-42. [PMID: 8059722]

63. Low KG, Fleisher C, Colman R, Dionne A, Casey G, Legendre S. Psychosocial variables, age, and angiographically-determined coronary artery disease in women. Ann Behav Med. 1998;20:221-6. [PMID: 9989330]

64. Julkunen J, Salonen R, Kaplan GA, Chesney MA, Salonen JT. Hostility and the progression of carotid atherosclerosis. Psychosom Med. 1994;56:519-25. [PMID: 7871107]

65. Detrano RC, Doherty TM, Davies MJ, Stary HC. Predicting coronary events with coronary calcium: pathophysiologic and clinical problems. Curr Probl Cardiol. 2000;25:374-402. [PMID: 10849509]

66. Doherty TM, Asotra K, Fitzpatrick LA, Qiao JH, Wilkin DJ, Detrano RC, et al. Calcification in atherosclerosis: bone biology and chronic inflammation at the arterial crossroads. Proc Natl Acad Sci U S A. 2003;100:11201-6. [PMID: 14500910]

67. Nemeroff CB, Widerlöv E, Bissette G, Walléus H, Karlsson I, Eklund K, et al. Elevated concentrations of CSF corticotropin-releasing factor-like immunoreactivity in depressed patients. Science. 1984;226:1342-4. [PMID: 6334362]
68. Di Somma C, Pivonello R, Loche S, Faggiano A, Marzullo P, Di Sarno A, et al. Severe impairment of bone mass and turnover in Cushing's disease: comparison between childhood-onset and adulthood-onset disease. Clin Endocrinol (Oxf). 2002;56:153-8. [PMID: 11874405]

69. Canalis E, Giustina A. Glucocorticoid-induced osteoporosis: summary of a workshop. J Clin Endocrinol Metab. 2001;86:5681-5. [PMID: 11739419]

70. Dennison E, Hindmarsh P, Fall C, Kellingray S, Barker D, Phillips $\mathrm{D}$, et al. Profiles of endogenous circulating cortisol and bone mineral density in healthy elderly men. J Clin Endocrinol Metab. 1999;84:3058-63. [PMID: 10487665]

71. Costa P, McCrae R. Depression as an enduring disposition. In: Schneider L, Reynolds C, Lebowitz B, Friedhoff A, eds. Diagnosis and Treatment of Depression in Late Life: Results of the NIH Consensus Development Conference. Washington, DC: American Psychiatric Pr; 1993:155-67.

72. Usala PD, Hertzog C. Evidence of differential stability of state and trait anxiety in adults. J Pers Soc Psychol. 1991;60:471-9. [PMID: 2027081]

73. Williams RB Jr, Barefoot JC, Haney TL, Harrell FE Jr, Blumenthal JA, Pryor DB, et al. Type A behavior and angiographically documented coronary atherosclerosis in a sample of 2,289 patients. Psychosom Med. 1988;50:139-52. [PMID: 3375404]

\section{CME while you keep up with medicine}

\section{Free CME} to Subscribers and Members

\section{http://cme.annals.org}
File Edit View Favorites Tools Heb
(7) $x$ त 20 search
(2) 8
因鮟

Annals of Internal Medicine CME

Estabished in 1927 by the American College of Physicians

Current Report for William Osler

\section{Active CME Courses}

to

Course Name All courses $>$ Courses by Subject $>$ Endocrinology, Oiabetes, and
Metabolism $>$ en Evaluatoon of the Maior Commercial Weiaht Loss proarams in the United States

\section{Contents of this course}

SOURCE ARTICLE: Systematic Review: An Evaluation of

Major Commercial Weight Loss Programs in the United

States [Abstract] [Full textl [POF]

QUIZ: An Evaluation of the Major Commercial Weight

Loss Programs in the United States [Quiz]

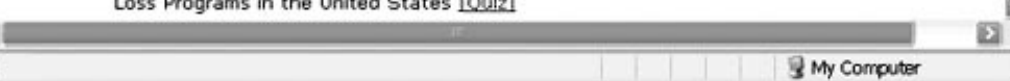

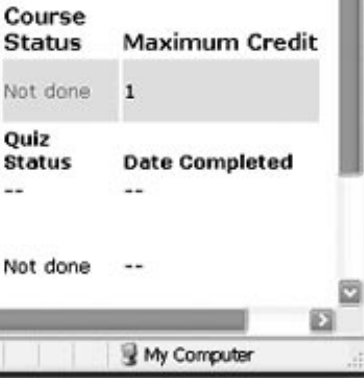

Course Not done Quiz

Date Completed 


\section{Annals of Internal Medicine}

Current Author Addresses: Drs. Diez Roux and Ranjit: Department of Epidemiology, School of Public Health, University of Michigan, 1214 South University, 2nd Floor, Ann Arbor, MI 48103.

Dr. Powell: Department of Preventive Medicine and Department of Behavioral Sciences, Rush University Medical Center, Suite 470, 1700 West Van Buren, Chicago, IL 60612.

Dr. Jackson: Department of Public Health Sciences, Wake Forest University School of Medicine, Medical Center Boulevard, Winston-Salem, NC 27157.

Dr. Lewis: Department of Preventive Medicine, Rush University Medical Center, Suite 470, 1700 West Van Buren, Chicago, IL 60612.

Dr. Shea: Departments of Medicine and Epidemiology, Columbia University, 630 West 168th Street, New York, NY 10032.

Dr. Wu: National Heart, Lung, and Blood Institute, National Institutes of Health, 2 Rockledge Center, Room 8218, 6701 Rockledge Drive, Bethesda, MD 20892-7938.
Author Contributions: Conception and design: A.V. Diez Roux, N. Ranjit, L. Powell, S. Jackson, S. Shea.

Analysis and interpretation of the data: A.V. Diez Roux, N. Ranjit, L. Powell, S. Jackson, C. Wu.

Drafting of the article: A.V. Diez Roux, N. Ranjit.

Critical revision of the article for important intellectual content: A.V. Diez Roux, N. Ranjit, L. Powell, S. Jackson, T.T. Lewis, S. Shea, C. Wu. Final approval of the article: A.V. Diez Roux, N. Ranjit, L. Powell, S. Jackson, T.T. Lewis, S. Shea, C. Wu.

Provision of study materials or patients: A.V. Diez Roux, S. Shea, S. Jackson.

Statistical expertise: A.V. Diez Roux, N. Ranjit, C. Wu.

Obtaining of funding: A.V. Diez Roux, S. Shea.

Collection and assembly of data: A.V. Diez Roux, S. Jackson, S. Shea. 